1614 ANALGESIA FOR PAINFUL PROCEDURES IN CHILDREN. A SURVEY OF CURRENT PRACTICE IN SOUTH-WEST LONDON HOSPITALS

doi:10.1136/archdischild-2012-302724.1614

'D Son, ${ }^{2}$ Liu. 'Paediatrics, Queen Mary's Hospital for Children, St Helier Hospital, Carshalton, UK; ${ }^{2}$ University of Heidelberg, Heidelberg, Germany

Background and Aims Knowledge about safe and effective management of pain in children is well known and documented. There is still a gap between knowledge and everyday practice. It seems children are still getting less analgesia than adults and newborn and infants less than children.

We conducted an audit/survey to get an overview of current analgesia practice for painful procedures in cildren.

Methods We used a questionnaire, in a paper and also online format, and distributed it to nursing and midwifery staff, Paediatric and GP junior doctors, and consultants working in Paediatric departments in hospitals in the South West of London. It included general questions about the perception of pain and also specific scenarios looking into the use of analgesia for a variety of procedures in children of different ages.

Results The amount of analgesia used was highest in the age group over one year and lowest in the newborn and one to four months groups. Throughout the different age groups, venepunctures were among the procedures when analgesia was used most often. Analgesia for intramuscular injections and lumbar punctures was never or only rarely used in the groups up to 4 months. Regardless of age, the procedure most commonly performed without analgesia was intramuscular injections.

Conclusions Use and knowledge of analgesia for painful procedures in children is still not optimal. We suggest that Paediatric department should offer better training for junior staff and also include a session on this topic as part of departmental induction programmes for new staff.

\section{EFFECTS OF GLUCOSE AND NON-NUTRITIVE SUCKING ON PAIN PERCEPTION}

doi:10.1136/archdischild-2012-302724.1615

S Beken, I Hirfanoglu, K Gücüyener, E Ergenekon, Ö Turan, N Altuntaş, E Kazancı, S Ünal, F Kulalı, E Önal, C Türkyılmaz, E Koç, Y Atalay. Gazi University Hospital, Ankara, Turkey

Background and Aim Sweet tasting solutions and non-nutritive sucking are strong pain reducers for newborns. This study aimed to investigate effects of $30 \%$ glucose solution and non-nutritive sucking on amplitude of pain perception with pain scale, stress detector and near infrared spectroscopy (NIRS) during and after venipuncture.

Method Term newborns were randomised into two groups before venipuncture for bilirubin measurement.

Group 1 received 30\% dextrose,

Group 2 received sterile water before venipuncture.

Recordings of skin conductance algesimeter (SCA, Med-Storm Innovation, Norway) from foot and NIRS (NIRO 200 Hamamatsu, Japan) from head were obtained starting 7 minutes before venipuncture until 7 minutes after. PAIN scores were obtained during and 7 minutes after procedure. Non-nutritive sucking was provided throughout the study.

Results 25 patients were included. Median PAIN scores were similar in both groups during venipuncture 5 (1-8) in Group 1, and $6(1-10)$ in Group 2. Scores were decreased significantly seven minutes after procedure in both groups; as $1(0-1)$ and $3(1-3)$ in Group 1 and 2 respectively. In Group 1, cerebral blood volume (CBV) was increased from baseline after the procedure $(p=0.008)$ however in Group 2 there was a decrease in CBV from baseline without statistical significance. Cerebral blood flow (CBF) was increased from baseline in both groups without statistical significance. SCA values were slightly increased from 0.23 to 0.29 in Group 1 and from 0.23 to 0.59 in Group 2.

Conclusion Nonnutritive sucking and $30 \%$ glucose attenuate pain and stress responses during venipuncture however cerebral effects are open to investigation.

\section{PAIN EVALUATION IN PRETERM INFANTS USING SKIN CONDUCTANCE ALGESIMETER}

doi:10.1136/archdischild-2012-302724.1616

'M Ahmed, 'D Sobithadevi, 'S Mostafa, 'P Pore, 2J Maiden, ${ }^{2} \mathrm{~S}$ Boswell, 'M Molnar, ${ }^{3}$ T Reynolds. 'Paediatrics; ${ }^{2}$ Research Nurse; ${ }^{3}$ Clinical Chemistry, Burton Hospitals NHS Foundation Trust, Burton Upon Trent, UK

Background Assessment of pain is a challenge in neonatal setting. Visual, behavioural and physiological pain scales are not always reliable in premature infants. Few studies with limited sample size have been published on the reliability and efficacy of Skin Conductance Algesimeter (SCA) in monitoring pain in infants and children.

Aim To identify the clinical usefulness of SCA as a reliable and valid measure of pain intensity and stress response in preterm infants.

Methods Parents of all preterm infants admitted to the neonatal unit were invited to participate in the study. The usefulness of SCA was compared with the simultaneous measurement of 'Premature Infant Pain Profile' (PIPP) and 'Face, Legs, Activity, Cry and Consolability (FLACC) scores during invasive and/or painful procedures.

Results 46 measurements were recorded from 31 patients. The gestational age at birth ranged from $27+5$ from $35+1$. Mean PIPP scores Pre: $3.063 \pm 1.272$, Pro: 9.175 \pm 3.761 , Post 4.275 \pm 1.506 . Twotailed Paired t-test Pre - Pro, $t=10.82, \mathrm{P}<0.001$; Pre - Post, $\mathrm{t}=4.19$, $\mathrm{P}<0.001$. Mean FLACC scores Pre: $0.713 \pm 1.198$, Pro: $5.925 \pm 2.99$, Post: 0.8625 \pm 1.0919 . Two-tailed Paired t-test Pre - Pro, $t=9.51$, $\mathrm{P}<0.001$; Pre - Post, $\mathrm{t}=0.67, \mathrm{P}=0.507$. Some correlations between SCA results and PIPP/FLACC did give statistically significant correlation coefficients.

Conclusions PIPP and FLACC scores were statistically significantly increased during the procedures. Further research is needed to ascertain the usefulness of SCA in preterm infants.

\section{ADMINISTRATION OF ROPIVACAINE WITH LOW DOSE KETAMINE REDUCES CYTOKINE EXPRESSION AFTER MAJOR ABDOMINAL OPERATION IN NEWBORN WITH CONGENITAL VISCERO-ABDOMINAL DISPROPORTION}

doi:10.1136/archdischild-2012-302724.1617

D Dmytriiev. Anesthesiology and Intensive Care, Vinnitsa National Medical University, Vinnitsa, Ukraine

Background Inflammation and nociceptive sensitization are hallmarks of tissue surrounding surgical incisions. Our studies were directed towards determining if administration ropivacaine with low dose ketamine alter cytokine production after major abdominal operation in newborn with congenital viscero-abdominal disproportion.

Methods A 39 children after major abdominal operation was used to measure the effects of infiltrative administration ropivacaine $0.2 \%$ with low dose ketamine $(0.1 \mathrm{mg} / \mathrm{kg}$ i.v. $)$ administration on cytokine production in blood 45 minutes, 4 hours after operation. We examination 30 patient, undergoing major abdominal operation in children, first group receive combination ropivacaine with low dose ketamine, second group receive morphine ( $0.1 \mathrm{ml}$ per year). For statistical analysis 2 tests were used. 